\title{
Pregnancy with cardiac disease: a retrospective five year study in a teaching hospital
}

\section{Manohar Rangaswamy*, Pradeep Musale Ramachandra}

Department of Obstetrics and Gynaecology, Mandya Institute of Medical Science, Karnataka, India

Received: 12 March 2016

Accepted: 12 April 2016

\section{*Correspondence:}

Dr. Manohar Rangaswamy,

E-mail: manoharrangaswamy@gmail.com

Copyright: (c) the author(s), publisher and licensee Medip Academy. This is an open-access article distributed under the terms of the Creative Commons Attribution Non-Commercial License, which permits unrestricted non-commercial use, distribution, and reproduction in any medium, provided the original work is properly cited.

\section{ABSTRACT}

Background: Prevalence of heart disease in pregnancy is found to vary between $0.3 \%-3.5 \%$. Heart disease is one of the 3 major indirect causes of maternal mortality in India.

Methods: This is a retrospective study conducted in department of OBG, Mandya Institute of Medical Science, India. Mandya for a period of five years from January 2011 to December 2015.All cases of cardiac disease during pregnancy admitted during this period will be included in the study. All case records will be obtained from medical record section and carefully analysed to find out the incidence, various types of cardiac diseases, its relation with respect to duration of pregnancy and its outcome in relation to mode of delivery, birth weight, maternal and perinatal morbidity. Results: Cardiac disease was more commonly present among Primigravida (53.8\%) which correlates with the study conducted Mahesh et al (52.7\%). Rheumatic heart disease (RHD) was the commonest cardiac lesion, which was also found to be the major form of heart disease in various studies. Mitral stenosis $(38.6 \%)$ is the most common RHD $.65 .3 \%$ (34 cases) was delivered by vaginal route and 34.6\% (18 cases) were delivered by LSCS.

Conclusions: Thus good antenatal care including more frequent antenatal check-up, educating the patient regarding the various complications and taking the physician help during antepartum or intrapartum or postpartum period will definitely reduce the maternal complications associated with it.

Keywords: Rheumatic heart disease, Pregnancy, Congenital heart disease, Mitral stenosis

\section{INTRODUCTION}

Prevalence of heart disease in pregnancy is found to vary between $0.3 \%-3.5 \%{ }^{1}$ Rheumatic heart disease still remains commonest etiological factor for heart disease complicating pregnancy. ${ }^{2}$ Cardiac output increases by 30 $50 \%$ during pregnancy and a further increase during labour and delivery imposes a burden on the diseased heart leading to complications and death. ${ }^{3}$ Cardiac disorders contribute to approximately $20.5 \%$ of maternal deaths. Neonatal complications were noted in $20 \%$ of the pregnancies with heart disease.

Heart disease is one of the 3 major indirect causes of maternal mortality in India. Maternal mortality varies directly with functional class, $0.4 \%$ for New York heart association(NYHA) class 1 and II and $6.8 \%$ for class III and IV. ${ }^{3}$ If atrial fibrillation is present, the risk of mortality rises by another $5-10 \%{ }^{4}$

\section{METHODS}

This is a retrospective study conducted in department of OBG, Mandya Institute of Medical Science, Mandya, India, for a period of five years from January 2011 to December 2015. All cases of cardiac disease during pregnancy admitted during this period will be included in the study. All case records will be obtained from medical record section and carefully analysed to find out the incidence, various types of cardiac diseases, its relation 
with respect to duration of pregnancy and its outcome in relation to mode of delivery, birth weight, maternal and perinatal morbidity.

The objective of the study is to find out the incidence and various cardiac diseases during pregnancy, the clinical presentations of various cardiac conditions and to find out the maternal and perinatal outcome.

\section{Inclusion criteria}

- All cases of pregnancy with cardiac disease diagnosed before or during pregnancy admitted to OBG ward

- Period of gestation $>28$ weeks

- Live foetus

\section{Exclusion criteria}

- $\quad$ Period of gestation $<28$ weeks

- Intrauterine death foetus

\section{RESULTS}

In the study 38 cases $(73 \%)$ were found in the age group of 20-25 years (Table 1 ).

Table 1: Incidence of cardiac disease according to maternal age.

\begin{tabular}{|ll|}
\hline Age & No. of cases $(\mathbf{5 2})$ \\
\hline$<19$ years & 2 \\
\hline $20-25$ years & 38 \\
\hline $26-30$ years & 8 \\
\hline $30-35$ years & 2 \\
\hline$>35$ years & 2 \\
\hline
\end{tabular}

In our study cardiac disease was found in 28 cases $(53.8 \%)$ followed by gravida 2 in about 18 cases $(34.6 \%)$ (Table 2).

Table 2: Incidence of cardiac disease with respect to gravida.

\begin{tabular}{|l|l|}
\hline Gravida & No. of cases(52) \\
\hline Primi & 28 \\
\hline Gravida 2 & 18 \\
\hline Gravida 3 & 4 \\
\hline Gravida 4 & 1 \\
\hline Gravida 5 & 1 \\
\hline
\end{tabular}

36 cases $(69.2 \%)$ presented with NYHA class I, 16 cases $(30.7 \%)$ were of NYHA class II and one cases presented with NYHA class III (Table 3).
Table 3: Incidence of cardiac disease with respect to NYHA classification.

\begin{tabular}{|ll|}
\hline NHYA Classification & Incidence of cardiac disease \\
\hline NYHA Class I & 36 \\
\hline NYHA Class II & 16 \\
\hline NYHA Class III & 1 \\
\hline NYHA Class IV & Nil \\
\hline
\end{tabular}

Rheumatic heart disease contributed to 44 cases $(84.6 \%)$ followed by congenital heart disease in about 8 cases (15.4\%) (Table 4).

Table 4: Incidence of cardiac disease in relation to type of lesion.

\begin{tabular}{|ll|}
\hline Type of cardiac lesion & No. of cases(52) \\
\hline RHD & 44 \\
\hline CHD & 8 \\
\hline
\end{tabular}

Mitral stenosis was the commonest cardiac lesion in RHD cases found in 17 cases $(38.6 \%)$, followed by mitral regurgitation in 14 cases $(31.8 \%)$ (Table 5$)$.

Among the 8 congenital heart diseases, post ASD closure $4(50 \%)$ cases, followed by ASD $2(25 \%)$ cases and VSD 1 case were found (Table 6).

Table 5: Rheumatic heart disease (44 cases).

\begin{tabular}{|l|l|}
\hline Type of lesion & No. of cases (44) \\
\hline Mitral regurgitation & 14 \\
\hline Mitral stenosis & 17 \\
\hline $\begin{array}{l}\text { Mitral regurgitation with tricuspid } \\
\text { regurgitation }\end{array}$ & 3 \\
\hline Mitral stenosis with mitral regurgitation & 6 \\
\hline Mitral valve repair [MVP] & 2 \\
\hline Mitral stenosis with PAH & 1 \\
\hline Mitral valve prolapse with Takayasu arteritis & 1 \\
\hline
\end{tabular}

Table 6: Congenital heart disease ( 8 cases).

\begin{tabular}{|ll|}
\hline Congenital heart disease & No of cases \\
\hline Atrial septal defect & 2 \\
\hline Ventricular septal defect & 1 \\
\hline ASD with PDA & 1 \\
\hline Post ASD closure & 4 \\
\hline
\end{tabular}

Out of 52 cases, $49(94.2 \%)$ cases were present between 38-42 weeks of gestation (Table 7).

49 cases $(94 \%)$ were of term gestation and 3 cases $(6 \%)$ presented by preterm gestation. Colour of liquor was clear in 45 cases and meconium stained liquor in 7 cases (Table 8). 
Table 7: Incidence of cardiac disease with respect to period of gestation.

\begin{tabular}{|ll|}
\hline Period of gestation in weeks & No. of cases (52) \\
\hline $28-32$ & 1 \\
\hline $33-37$ & 2 \\
\hline $38-42$ & 49 \\
\hline
\end{tabular}

Table 8: Incidence of liquor colour among cardiac disease.

\begin{tabular}{|ll|}
\hline Liquor colour & No. of cases \\
\hline Clear & 45 \\
\hline Meconium & 07 \\
\hline
\end{tabular}

Out of 52 cases, 34(65.3\%) cases were delivered by vaginal route. 18 cases $(34.6 \%)$ were delivered by LSCS, vaccum delivery in 17 cases $(32.6 \%)$, FTND in 14 cases $(26.9 \%)$ and 3 cases $(5.7 \%)$ were delivered by PTVD.

Of 18 cases of LSCS, 7 cases were of previous LSCS, 3 were done for IUGR, 2 were done for oligohydramnios, 3 were done for foetal distress, 1 for breech and one for previous history of GB syndrome. All cases of LSCS were done for obstetric indication only (Table 9).

Table 9: Incidence of delivery outcome in cardiac disease.

\begin{tabular}{|ll|}
\hline Incidence of delivery outcome & Percentage \\
\hline PTVD & $03(5.7 \%)$ \\
\hline FTND & $14(26.9 \%)$ \\
\hline Vaccum & $17(32.6 \%)$ \\
\hline LSCS & $18(34.6 \%)$ \\
\hline
\end{tabular}

Out of 52 cases, 28 cases were of birth weight between $2.5 \mathrm{~kg}$ to $3 \mathrm{~kg}$ (Table 10 ).

Table 10: Incidence of birth weight in cardiac disease.

\begin{tabular}{|ll|}
\hline Birth weight & No of cases (52) \\
\hline$<2.5 \mathrm{Kg}$ & 12 \\
\hline $2.5-3 \mathrm{~kg}$ & 28 \\
\hline $3-3.5 \mathrm{~kg}$ & 09 \\
\hline$>3.5 \mathrm{~kg}$ & 3 \\
\hline
\end{tabular}

Table 11: Relationship of maternal complication among cardiac disease.

\begin{tabular}{|ll|}
\hline Maternal complication & No. of cases \\
\hline Pulmonary edema & 1 \\
\hline Congestive cardiac failure & 1 \\
\hline
\end{tabular}

\section{DISCUSSION}

The present study was undertaken to evaluate the various cardiac diseases during pregnancy admitted during January 2011 to December 2015.

The prevalence of cardiac disease was 52 cases among 31,160 deliveries accounting for $0.16 \%$.

$73 \%$ of cases were present between 20 to 25 years.

Cardiac disease was more commonly present among Primigravida $(53.8 \%)$ which correlates with the study conducted Mahesh et al $(52.7 \%){ }^{6}$

According to NYHA classification, 36 cases were of NYHA Class I, 25 cases were of NYHA Class II and one case presented with NYHA Class III.

Rheumatic heart disease was the most common cardiac lesion, which was also found to be the major form of heart disease in various studies. Mitral stenosis (38.6\%) is the most common RHD which was also found to be similiar to study conducted by Bangal VB $(40 \%){ }^{4}$

Congenital heart disease was present in about $15.3 \%$ of cases which is similar to study conducted by Mahesh et al $(14.54 \%)^{6}$

Among Congenital heart disease Post ASD closure $(50 \%)$ was the commonest type.

$65.3 \%$ (34 cases) were delivered by vaginal route and $34.6 \%$ (18 cases) were delivered by LSCS which is comparable to study conducted by Sawhney et al. ${ }^{7}$ All cases of LSCS were done for obstetric indication only.

$76.9 \%$ (40 cases) of babies delivered were more than $2.5 \mathrm{~kg}$ and $23 \%$.

(12 cases) babies were less than $2.5 \mathrm{~kg}$ which is similar to study conducted by Puri $\mathrm{S}$ et al.

7 cases were admitted to NICU due to meconium aspiration (2 cases), preterm (4 cases), and mild birth asphyxia ( 1 case) and there were no perinatal mortality.

One case of Congestive cardiac failure and one case of acute pulmonary edema were admitted to ICU during postpartum period. Both cases were successfully treated and discharged uneventfully. Main causes for maternal mortality were due to pulmonary edema, atrial fibrillation and bacterial endocarditis according to study conducted by Laura et al. ${ }^{8}$

There was no maternal mortality during the study period. 


\section{CONCLUSION}

Managing a case of cardiac disease during pregnancy poses a great challenge to every obstetrician in a present day obstetrics, that to in a rural teaching hospital where cardiologist services might not be available. Thus good antenatal care including more frequent antenatal checkup, educating the patient regarding the various complications and taking the physician help during antepartum or intrapartum or postpartum period will definitely reduce the maternal complications associated with it.

Funding: No funding sources

Conflict of interest: None declared

Ethical approval: The study was approved by the Institutional Ethics Committee

\section{REFERENCES}

1. Pratibha D, Kiranmai D, Rani DU, Vani NG. J Obstet Gynecol India vol.59,No.1:Jan/feb 2009 pg 41-46

2. Oron G, Hirsch R, Haroush AB, Hod M, Gilboa Y, Davidi O, Bar J. Pregnancy outcome in women with heart disease undergoing induction of labor. BJOG,2004;111:669-75.

3. Hiralal K, Chaudhari S. Pregnancy complicated by maternalheart disease:a review of 281 women vani. J Obstet Gynecol India.2012;62(3):301-6.

4. Bangal VB, Singh RK, Shinde KK. Clinical study of heart disease complicating pregnancy. IOSR Jour of Pharmacy. 2012;2(4):25-8.

5. Puri S, Bharti A, Puri S, Mohan B, Bindal V, Verma S. Maternal Heart Disease and Pregnancy Outcomes. JK Science.2013;15(1):7-10.

6. Koregol M, Mahale N, Radhakrishna, Bhandary A. Maternal and perinatal outcomes of pregnancies complicated by cardiac disease. J Turkish German Gynaecol Asso.2009;10:30-4.

7. Sawney H, Aggarwal N, Suri V, Vaishta K, Sharma Y, Grover A. Maternal and perinatal outcome in rheumatic heart disease. Int J Gynaecol Ogstet.2003;80:9-14.

8. Laura L, Klein, Galan HL. In Cardiac disease in pregnancy. In management of the high risk pregnancy. Obstetrics and Gynaecology Clinics of North America.2004;31(2):429-59.

Cite this article as: Rangaswamy M, Pradeep

MR. Pregnancy with cardiac disease: a retrospective five year study in a teaching hospital. Int J Reprod Contracept Obstet Gynecol 2016;5:1589-92. 